\title{
The Use of Reading Strategies by Struggling English Language Learners
}

\author{
Ermi Ruziyana Md. Nordin, Azizah Rajab, Faizah Mohamad Nor, Norhiza Ismail
}

\begin{abstract}
Active readers use several approaches to comprehend what they read before, during, and after reading. These readers use their previous experience or information to reflect about the subject, guess the text meaning and apply their skimming and scanning skills to predict the overall meaning. However, for a struggling English language learner (ELL) applying this skill may pose as a real challenge especially when the text level becomes more difficult and they are interpreting unfamiliar texts. One of the factors that may contribute to this problem is the absence of reading strategies. Hence, in this study, five 12-years old ELLs from a School in Johor Bahru were involved to record their usage of reading strategies before and after the reading strategy instructions. The study incorporates the quantitative design and the data collected was analysed using SPSS 16. ELLS answered a set of questionnaires from an adapted survey of reading strategies (SORS) developed by Mokhtari \& Reichard (2002). The findings showed that despites their struggling in reading, these learners were able to apply some reading strategies to help them in reading English texts and marked differences in the frequency of reading strategies used at the end of the reading instruction in comparison to the early stage of the study.
\end{abstract}

Keywords: English Language Learners (ELLs), struggling readers, reading strategies, $E S L$

\section{INTRODUCTION}

$\mathrm{R}$ eading skill is irrefutably essential that an English Language Learner (ELL) should embrace. The deficiency in reading skill will eventually obstruct the language learning process specifically and the attainment of knowledge and information as a whole. Not only that, individuals' motivation to learn will be affected due to inability to read and comprehend messages in texts and that will prolong to affecting social and academic development in their future lives. Thus, a reader should be able to use multiple reading strategies to engage the schemata with the newly read information because reading itself is a cognitive activity in which the reader takes part in a conversation with the author through the text [1]. Although many researches have been carried out revolving around reading strategies use among ELL in Malaysia. However, less or little researches were done

Revised Manuscript Received on October15, 2019

* Correspondence Author

Ermi Ruziyana Md Nordin*, School of Education, Faculty of Social Sciences and Humanity, Universiti Teknologi Malaysia. Email: ermiruziyana@gmail.com

Azizah Rajab, Language Academy, Faculty of Social Sciences and Humanity, Universiti Teknologi Malaysia. Email: azizah@utm.my

Faizah Mohamad Nor, Language Academy, Faculty of Social Sciences and Humanity, Universiti Teknologi Malaysia. Email: m-faizah@utm.my

Norhiza Ismail, Language Academy, Faculty of Social Sciences and Humanity, Universiti Teknologi Malaysia. Email: m-nhiza@utm.my

in venturing the use of the strategies by struggling English learners centring the primary school children in Malaysia, which became the pillar of the study.

Hence, the main objective of this study is to investigate the differences of reading strategies use in reading English texts in before and after the implementation of reading strategies' instruction among struggling ELLs at primary school level.

\section{READING STRATEGIES}

Researchers mainly in the academic or teaching field in Malaysia, have tried to shed some lights on the usage of reading strategies in reading text in English and its effects on students' reading and understanding. Many researches were carried out to investigate the readers' use of metacognition or in other words, the reader's cognition about reading and the self-mechanisms they apply during reading [2]. Metacognitive awareness in reading is associated with the procedure of making connection or integration of ideas with the written information towards getting the gist. Active readers who could employ the metacognitive reading strategies were able to find ways in understanding the text when they were having difficulties. [3]

In addition, these researches highlighted the importance of reading strategies to assist and comprehend the text being read in second language or foreign language especially English as well. English language learners use the strategies to make learning more effective and improve comprehension [2]. In other words, strategies are processes used by the learner to enhance reading comprehension and overcome comprehension failures. [4]

Imperatively, ESL learners need to be aware of their reading strategies in order to aid their comprehension in the tasks assigned [1]. In improving struggling readers' comprehension and interest in their reading, they need to be taught so that the reading and the strategies are sensible to them [4]. However, these deficient learners read at different pace and possess limited vocabulary, hence equipping them with sufficient and relatable reading strategies may provide them opportunity to be better readers and lift their motivation to read.

\section{STRUGGLING READERS}

Struggling readers are readers who have common characteristics such as having difficulty decoding texts [5] and not comprehending what they read [6]. 
Apparently, struggling readers may fall into either one or both of the following categories which are , first, having problem to read at text level that require them to pronounce the words and sounds of letters.

Second, the lacking of comprehending ability where these learners are able to read words in text but were not able to make meaning. Garret [8], implied how do teachers identify struggling readers differ from the normal readers and the social aspects are also taken into account for instance the reading experience, the types of reading texts, and also the method of reading assessment. Significant to this, struggling English language learners from a primary school were involved in this study who had limited vocabulary, not understanding the text being read, difficulties in decoding texts, obtained low scores in standardised school reading comprehension tests, and also who were not able to provide responses as asked by the language teacher on the text being read. These readers were having similar characteristics as suggested earlier. [5-8].

\section{MATERIAL AND METHODS}

\section{A. Participants}

Five-Year 6 learners of a primary school in Johor Bahru, Johor, Malaysia were involved in this study namely $\mathrm{Fa}, \mathrm{Ai}$, $\mathrm{Zha}, \mathrm{Mu}$, and $\mathrm{Si}$ (pseudonyms). All learners were chosen based on their performance in Year 6 English Language Comprehension Test Paper and all of them scored below $30 \%$. The grade recorded was E, which is considered as the lowest grade in the test. The students were also selected based on their reading performance in class as observed by the subject teacher. The learners were involved in the series of reading strategies' instructions and answered the questionnaires of an adapted version of SORS developed by Mokhtari and Reichard (2002) [9] in pre and post of the reading strategies' instructions. The questionnaires were presented in both English and Bahasa Malaysia due to students' limitations in understanding English words and sentences. The researcher read the questions one by one and asked the learners for their understanding before they answered the questionnaires on their own. There is no time limitation for the learners to answer to ensure that conducive and non-threatening environment is provided.

The study uses a collection of a quantitative data to find out any improvement or changes of frequency in the use of reading strategies while reading English texts by the struggling ELLs. A survey questionnaire was conducted for the research and the questionnaire was taken and adapted from the survey developed by Mokhtari \& Reichard (2002) [9]. Three main areas were measured using the questionnaire namely Global Reading Strategies; Problem-Solving Strategies and Support Reading Strategies. The questionnaire applies 5-Likert scales, which are

1) "I never or almost never do this."

(2) "I do this only occasionally."

(3) "I sometimes do this." (About $50 \%$ of the time.),

(4) "I usually do this.", and

(5) "I always or almost always do this".

The scales were translated into Bahasa Malaysia to ensure that students understand the questions in their first language and were able to respond to the questions listed.
The data collected from the questionnaire was computed into SPSS 16 and the procedure of descriptive statistics was adopted to analyse the data by presenting and comparing the mean and frequency of the strategies used. Learners' scores were analysed individually in seeking for the differences of scores in pre and post instruction by individuals. On the other hand, the comparison of score differences among each learners had also been analysed in search of any similarities or differences practised by learners.

\section{FINDINGS}

Table I in the following, presents the paired sample statistics of questionnaires responses answered by the struggling ELLs in pre- and post- reading strategies' instructions. The scores in Table I were rated based on Oxford's classification [10]. The learners with the means of 3.5 and above are categorised as high strategy user. Meanwhile, the medium strategy user is grouped with the means between 2.5 and 3.4 and for low strategy user; means of 2.4 and below.

In the pre-instruction survey, three learners were categorised as low reading strategies users, while another two learners were of moderate users. After six months of instructions, learners answered the survey again and the means were recorded as the following. Four learners were rated as medium strategy users and one learner as high strategy user.

Table I: Paired sample statistics of the pre and post instructions by the struggling ELLs

\begin{tabular}{|c|l|c|c|c|c|}
\hline \multirow{2}{*}{ Pair } & Participants & Mean & N & $\begin{array}{c}\text { Std. } \\
\text { Deviation }\end{array}$ & $\begin{array}{c}\text { Std. Error } \\
\text { Mean }\end{array}$ \\
\hline \multirow{2}{*}{1} & Fa: Pre & 2.93 & 30 & 1.202 & 0.219 \\
\cline { 2 - 6 } & Fa: Post & 3.50 & 30 & 1.196 & 0.218 \\
\hline \multirow{2}{*}{2} & Ai: Pre & 2.20 & 30 & 1.495 & 0.273 \\
\cline { 2 - 6 } & Ai: Post & 3.23 & 30 & 1.851 & 0.338 \\
\hline \multirow{2}{*}{3} & Zha: Pre & 3.20 & 30 & 1.095 & 0.2 \\
\cline { 2 - 6 } & Zha: Post & 3.47 & 30 & 0.973 & 0.178 \\
\hline \multirow{2}{*}{4} & Mu: Pre & 2.37 & 30 & 1.159 & 0.212 \\
\cline { 2 - 6 } & Mu: Post & 2.87 & 30 & 1.137 & 0.208 \\
\hline \multirow{2}{*}{5} & Si: Pre & 1.37 & 30 & 0.49 & 0.089 \\
\cline { 2 - 6 } & Si: Post & 2.27 & 30 & 0.583 & 0.106 \\
\hline
\end{tabular}

Table II: Paired samples test of pre- and post-instruction reading strategies usage by struggling ELLs

\begin{tabular}{|c|c|c|c|c|c|c|c|c|}
\hline \multirow{3}{*}{ Pair } & \multicolumn{5}{|c|}{ Paired Differences } & \multirow{3}{*}{$\mathbf{t}$} & \multirow{3}{*}{ df } & \multirow{3}{*}{$\begin{array}{c}\text { Sig. } \\
2- \\
\text { tailed }\end{array}$} \\
\hline & \multirow[t]{2}{*}{ Mean } & \multirow{2}{*}{$\begin{array}{c}\text { Std. } \\
\text { Devia } \\
\text { tion }\end{array}$} & \multirow{2}{*}{$\begin{array}{l}\text { Std. } \\
\text { Error } \\
\text { Mean }\end{array}$} & \multicolumn{2}{|c|}{$\begin{array}{l}\text { 95\% Confidence } \\
\text { Interval of the } \\
\text { Difference }\end{array}$} & & & \\
\hline & & & & Lower & Upper & & & \\
\hline 1 & -0.567 & 1.073 & 0.196 & -0.967 & $\begin{array}{c}-0.16 \\
6\end{array}$ & -2.89 & 29 & 0.007 \\
\hline 2 & -1.033 & 1.450 & 0.265 & -1.575 & $\begin{array}{c}-0.49 \\
2\end{array}$ & -3.9 & 29 & 0.001 \\
\hline 3 & -0.267 & 1.112 & 0.203 & -0.682 & 0.149 & \begin{tabular}{|l|}
-1.31 \\
\end{tabular} & 29 & 0.199 \\
\hline 4 & -0.500 & 1.196 & 0.218 & -0.947 & $\begin{array}{c}-0.05 \\
3\end{array}$ & -2.29 & 29 & 0.03 \\
\hline 5 & -0.900 & 0.607 & 0.111 & -1.127 & $\begin{array}{c}-0.67 \\
3\end{array}$ & -8.12 & 29 & 0 \\
\hline
\end{tabular}


Table II above displays the paired t-test result in search to find the mean differences by each learners in pre and post-instruction. The variance are ranging from 0.267 to 1.033 while all $p$-values are smaller than $0.005(p<0.005)$ except for Zha .This posits that there are significant differences between the two stages of strategies being used by struggling ELLs.

\section{DISCUSSION}

The ELLs' frequency of reading strategy usage and the findings are further discussed based on means and $p$-values displayed in Table I and II. Learner Fa, showed a great increase in means from 2.93 to 3.50 . She had also recorded the highest number of means in post-instruction survey in comparison to other learners in the group. This indicated that the learner was able to keep up with the strategies' instructions taught and was aware of her usage when reading Englist texts. The $p$-value which is 0.007 shows a significant different of reading strategies used at the end of the instruction. Another learner, Ai, had advanced to being a medium user of reading strategies who had recorded means at 3.23 in his post-instruction survey where he started at 2.20. From his scores, he showed that he was able to employ the strategies more often after the instructions. His $p$-value was 0.01 and it proves that there is a significant difference in his usage of reading strategies. Greatly, he scored the highest mean difference of 1.033 among his peers. Learner Si, however in pre- and post-instructions survey is grouped as low frequency user though he had shown increment of means in his reading strategies usage which was from 1.37 to 2.27 . The difference of means in pre and post instruction by $\mathrm{S}$, is 0.90 while his $p$-value was recorded at 0.00 . His improvement highlights the importance of teaching learners the strategies in reading to struggling learners and they were able to follow and practise the strategies but at different level and capacity. The means of reading strategies used by $\mathrm{Mu}$, postulates that he had improved the usage and was categorised as the medium user. The $p$-value of 0.003 significantly demonstrates the difference between the two scores of the survey. As he started at 2.37 and recorded 2.87 in his post-survey, his means shot the difference of 0.50 . Though he recorded a slight increase, it is vital for him to know and experience the improvement to boost his confident and to promote frequent application of the strategies. Alternately, Zha, exhibits the lowest growth in mean difference in his usage of reading strategies. He was categorized as a medium strategy in pre and post instructions and his $p$-value is 0.199 . This reckons that there was no significant difference in his practice of reading strategies. Nonetheless, it is providing a different insight to the teacher where different learners learned differently and to look deeper on other factors that might appear which had affected his development. The result provides many ideas that the language teacher can benefit from. First, the struggling learners were able to monitor and aware of their reading strategies use even though they found it is difficult to read the English texts. This means that struggling learners are aware of their own learning and process of reading, thus becoming more understanding after instructions. Most importantly, most of the learners exhibited growth in using the reading strategies to understand the text better. Some improved their strategies in the run to progress in reading. Second, different learners took up the instructions at different levels and they were influenced variedly based on individuals' performance. Some learners were able to achieve great changes by advancing to another level and attained big difference in the means, meanwhile some learners progressed quite gradually by demonstrating little variance recorded in their means. The findings in the study is parallel to the suggestion that metacognitive reading strategies instructions have an impact and work as a device to improve learners' reading comprehension [3]. Briefly, it is important to highlight the awareness and the reasons of employing the strategies to ELLs despites of them having deficiency in reading. To add, struggling ELLs needed scaffolding and clear modelling by teachers for them to be able to progress and employ strategies instructed and exposed to them. Pezhman and Moomala (2013) noted that instructors need to take into account the learners' strategies to support less successful learners in achieving and progressing in the focused language. By exposing the not fully proficient readers to the strategies through reading instructions, it is proposed that learners' behaviour towards independent reading and their understanding of reading process will be affected [11]. Thus, the notion supports the findings of this study where most struggling ELLs exhibited growth in the reading strategies awareness after the instructions.

\section{CONCLUSION}

Throughout this study, struggling ELLs demonstrated progress in the usage of reading strategies to assist them in reading and comprehending the English texts. The increase of usage and awareness responded by the ELLs in the study using the questionnaire data exhibited a pattern that through a habitual process and exposure, learners can be taught to use reading strategies and eventually are aware to use the strategies before, during, and after reading. This practice is hoped to become routine and learners could later be autonomous in their own reading activity and learning in English. In this regard, teachers should plan reading lessons with the incorporation of reading strategies and apply them recurrently to struggling ELLs. This finding is paralleled to teachers should also show students how to combine strategies during their reading [12]. Students' interests' and inclination towards strategies should also be considered because different learners learn inversely. Essential to note that there is no single strategy that suits all learners but multiple strategies could be stimulating and engaging. Next, the instruction of reading involving English language learners specifically struggling learners is never a laidback process. English language teachers need to be flexible and resilient in planning the reading instructions and cognisant of the reading strategies' exposure to struggling ELLs. The learners should be exposed to various types of reading strategies that can be practically used in reading [13] despites of their language learning ability.

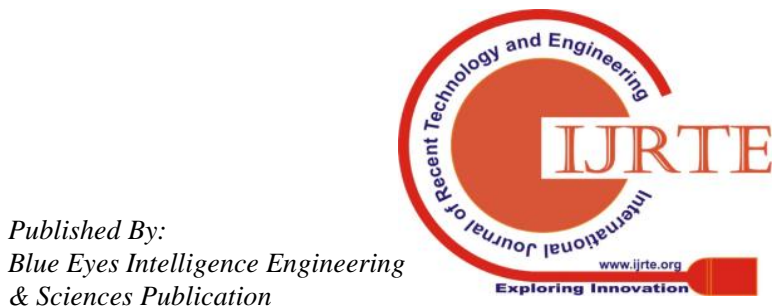


This corroborates the Nurazila et.al assertion that to increase students' awareness of such strategies, teachers play a vital role in helping to use the "given strategy". Teachers need to be knowledgeable, and ready to adapt to the well-being of learners especially the struggling ones because teachers need to have a clear comprehension of the strategies' practice to be able to transfer the knowledge to the learners [12]. Time allocation is another main area that English teachers need to consider because struggling learners have shorter attention span in comparison to their peers in the classrooms. Hence, repetitive lessons would be necessary to enhance their practice and memory. The lesson should be made short but precise and creative to maximise the efficiency of the lesson so that the objectives could be achieved, if not wholly, then partially would be a great achievement by these learners.

Crucially, the awareness and practice of strategies in reading English texts should be emphasized. ELLs, particularly should be able to understand the process of reading and suitable methods that could enlighten them to create comprehension before, during, and after reading. Without strategies in reading, readers will get lost in definition.

\section{ACKNOWLEDGEMENT}

Thank you to the participants involved in the study. Special thanks to Assoc. Prof . Dr. Azizah, Assoc. Prof. Dr. Faizah, Dr. Norhiza and Faculty of Humanity and Social Science, Universiti Teknologi Malaysia for the support and guidance.

\section{REFERENCES}

1. Pezhman. Z., Moomala. O., "The relationship between reading comprehension and reading strategy use among malaysian ESL learners," International Journal of Humanities and Social Science., vol. 3, No. 13, July 2013, pp. 187-193.

2. Nurazila. A. A., Suzana. Ab. R., Etty. H. H., Nor. A. A., Hasfazilah. A., Samsiah. B., Mohd. Rizaimy. S., "The reading strategies awareness among English as a Second Language (ESL) Learners in Malaysia's University," Theory and Practice in Language Studies, vol. 1, issue 7, 2011, pp. 778-784.

3. Mohammad. R. A., Hairul. N. I., Muhammad. K. K. A., "The importance of metacognitive reading strategy awareness in reading comprehension," English Language Teaching, vol. 6, no. 10, 2013 , pp. 235-244.

4. Latisha. A. S., Surina. N., "The characteristics of struggling university readers and instructional approaches of academic reading in Malaysia," International Journal of Human Sciences, vol. 8, issue 1, 2011.

5. Scanlon. D. M., Anderson. K. L., Sweeney. J. M., "Early intervention for reading difficulties: The interactive strategies approach," Guilford Publications, 2016.

6. Swanson. H. L., "Do semantic memory deficiencies underlie learning readers' encoding processes?," Journal of Exceptional Child Psychology, vol. 41, issue 3, 1986, pp. 461-488.

7. Worthy. J., Invernizzi. M. A., "Linking reading with meaning: A case study of a hyperlexic reader," Journal of Reading Behavior, vol. 27, issue 4, 1995, pp. 585-603.

8. Garrett. J., "The reading experience: how struggling and non-struggling readers differ," St. John Fisher College, 2012.

9. Mokhtari. K., Reichard. C. A., 'Assessing students' metacognitive awareness of reading strategies Oklahoma State University,” vol. 94, no. 2, 2002, pp. 249-259.

10. Oxford. R. L., "Language learning strategies: What every teacher should know," New York: Newbury House Publishers, 1990.

11. Joy. J., "Developing strategic readers in elementary school," Reading Psychology, vol. 24, pp. 25-55, 2003.
12. Nguyen. T. B. T., "Reading strategies used by Vietnamese EFL and ESL university students," VNU Journal of Foreign Studies, vol. 34, no. 2, pp. 111-124, 2018

13. Semtin. S.A., Maniam. M., "Reading strategies among ESL Malaysian secondary school students," vol. 4, no.2, June 2015, pp. 54-61.

\section{AUTHORS PROFILE}

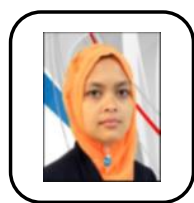

Ermi Ruziyana Md Nordin is a teacher in a primary school in Johor Bahru, Johor, Malaysia. she graduated from University Malaya with in Teaching English as a Second Language (Hons). She has 10 years experience of teaching English in primary schools.

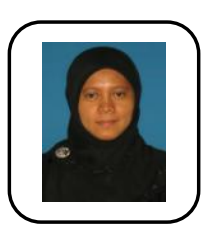

Azizah Rajab is Associate Professor at the Language Academy, University Teknologi Malaysia, Johor Bahru Campus. She obtained her PhD in Applied Linguistic from Leicester University, UK in 1996. She is with UTM for more than 31 years and currently active in research related to Second Language, Educational Psychology, Higher Education and Social Science.

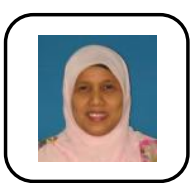

Associate Professor Faizah Mohamad Nor graduated from University of Malaya with a Bachelor's degree in Mathematics. She later pursued a Diploma in Education (T.E.S.L/ Math) from University of Malaya, M. Sc (T.E.S.P.) from Aston University (U.K.) and $\mathrm{PhD}$ in T.E.S.L. (Universiti Teknologi Malaysia). Her research interests are ELT Methodology, Teacher Training, and Language and Literacy.

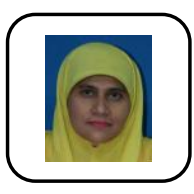

Dr. Norhiza Ismail is a senior lecturer in Universiti Teknologi Malaysia (UTM). She received her doctorate in teaching English as a Second Language (TESL) in 2014. She has 30 years of teaching experience, teaching TESL undergraduate, as well as supervising Masters and PHD students. Her publications include Learning Citation Conventions Through Teaching Applications: From Students' Perspectives (2018), Academic English Skills: Fulfilling Students' Needs Through A Needs' Analysis Study (2017) and a Preliminary Investigation On Undergraduate Academic Writing Course Through Qualitative Lens (2016). Her research interests are Language Learning Strategies, Reading Strategies, and Metacognitive Strategies. She was a member of the International Literacy Association. 